\title{
THE VALIDITY OF RAPID DETERMINATIONS OF THE OSMOTIC PRESSURE OF PROTEIN SOLUTIONS ${ }^{1}$
}

\author{
By H. S. WELLS, D. G. MILLER, JR., AND B. M. DRAKE \\ (From the Laboratory of Physiology, Vanderbilt University School of Medicine, Nashville)
}

(Received for publication June 18, 1934)

The methods for measuring osmotic pressure which are at present acceptable to the more critical investigators $(1,2)$ often require weeks or months to carry out. Membranes must be selected with so slight a degree of permeability that there can be no question of the escape of solute molecules into the outer solution. Many days may be required to attain equilibrium, and it is considered good practice to maintain the final pressure over a long period in order to make certain that a true equilibrium has been established. When protein solutions are used it is customary to preserve them against putrefactive or other changes by conducting the experiment at $0^{\circ} \mathrm{C}$. However, not all protein solutions remain stable under these conditions; and, in fact, no method has as yet been found which will preserve blood serum or other biological fluids in an osmotically stable condition for a sufficient period to allow the determination of the original osmotic pressure by the standard methods.

The use of relatively permeable membranes in attempts to measure the osmotic pressure of serum proteins by the various rapid methods now in common use for clinical investigations is a questionable practice, unless it can be demonstrated conclusively that these membranes are strictly semipermeable. In the absence of a standard preparation of serum of known osmotic pressure it will be necessary, alternatively, to demonstrate the accuracy of such rapid methods by tests carried out with some other protein solution, the osmotic pressure of which has been accurately determined by an orthodox method. It must further be shown that serum proteins remain in an osmotically stable condition during the time required for the determination. The data to be presented indicate that the rapid method in use in this laboratory $(3,4,5,6)$ for studies on bio-

1 This study has been aided by a Fluid Research Fund granted by the Rockefeller Foundation. logical fluids does indeed measure up to these criteria of reliability.

\section{PROCEDURES}

The determinations of the osmotic pressure were carried out as described previously, except that the osmometers, supported on convenient racks, were submerged below the surface of water in a bath, the temperature of which could be maintained constant within $\pm 0.05^{\circ} \mathrm{C}$. or better. The temperature of $0^{\circ} \mathrm{C}$. was maintained by the addition of cracked ice, thoroughly stirred with air and prevented from blanketing the osmometers by being held in the center of the bath behind a barrier of fine wire screen. Other temperatures below and above that of the room were obtained by a combination of cooling coils and heater or by the heater alone, in the usual manner. The necessity of maintaining a constant temperature is obvious when one considers that a change in temperature of $0.1^{\circ} \mathrm{C}$. or less will produce an appreciable change in volume of the solution, with a corresponding movement of the meniscus in the capillary tube of the osmometer.

It has been found that blood serum will usually undergo irreversible changes at $0^{\circ} \mathrm{C}$. Osmotic equilibrium cannot be established, the pressure continues to fall, and a definite precipitation of protein occurs. At temperatures above $25^{\circ} \mathrm{C}$., on the other hand, serum, when collected in the usual way without special aseptic precautions, will occasionally, but by no means invariably, develop putrefactive changes within the time necessary for the attainment of equilibrium. In the studies on the relation of the osmotic pressure to temperature, therefore, the pressure was determined first at the lowest temperature (which was never below $10^{\circ} \mathrm{C}$.). A very few hours at each of the higher temperatures would then suffice for the attainment of a new equilibrium, without danger of putrefactive changes. In a few instances the temperature was again lowered to the original level and the pressure redetermined. The fact that these two determinations at the original low temperature gave values which checked well within the limits of error of the method was considered as positive evidence that the serum had not undergone irreversible changes during the course of the experiment.

Hemoglobin solutions may be kept almost indefinitely at $0^{\circ} \mathrm{C}$. as Adair (1) found; but putrefaction occurs readily at higher temperatures. Errors due to such changes may be avoided if one conscientiously adheres to the rule that no pressure value shall be considered a true equilibrium pressure unless the meniscus of fluid in the osmometer can be kept at an absolutely constant level 
(at constant temperature) for a period of at least two hours. A continuous fall of the pressure, no matter how gradual, which persists long after the time usually required to attain equilibrium, is prophetic of the obvious putrefaction or precipitation of protein which is to follow.

Membranes of several specific permeability ranges were prepared by varying the concentration of alcohol in which the dry collodion sacs were allowed to swell. For this purpose alcohol-water solutions were prepared as follows: 91 cc. of absolute alcohol (density, $d_{4}{ }^{20}=0.7816$ ) plus 9 cc. water, giving a solution of density 0.8124 and weight per cent 88.79 and providing membranes in the specific permeability range (3) of 1 to $3 \times 10^{-6} ; 93 \mathrm{cc}$. alcohol plus $7 \mathrm{cc}$. water, density 0.8062 , weight per cent 91.14 , permeability range 6 to $12 \times 10^{-8} ; 95$ cc. alcohol plus 5 cc. water, density 0.7997 , weight per cent 93.50 , permeability 20 to $57 \times 10^{-8}$; and $97 \mathrm{cc}$. alcohol plus 3 cc. water, density 0.7924 , weight per cent 96.10 , giving the range of permeability of 200 to $300 \times 10^{-8}$. Membranes of the latter group are usually distinctly permeable to serum proteins, but in one instance an equilibrium was attained, without leakage of protein. The "95alcohol" grade of membranes may be considered the standard, as they are the most practical to use for ordinary purposes. They have been employed throughout the present investigation, except for certain of the experiments reported in Table II.

In several instances, during the past few years, an ultrafiltrate of serum has been prepared for use as outer solution. Serum was ultrafiltered through the standard membranes, as defined above, at a pressure of 300 to $500 \mathrm{~mm}$. Hg. During the course of 2 or 3 hours, $1 \mathrm{cc}$. or more of ultrafiltrate was obtained. A fresh membrane was always employed for the measurement of osmotic pressure. While the use of the ultrafiltrate may give initial pressure readings which are much closer to the equilibrium values (within $30 \mathrm{~mm}$. of water, or thereabouts) the time required to attain equilibrium was not appreciably shortened in any of our experiments. The same equilibrium was obtained as when 0.9 per cent sodium chloride or Ringer-Locke's solution was used as the outer solution. Consequently there seems to be no advantage to be gained from the use of ultrafiltrates.

Hemoglobin solutions were prepared from oxalated human blood of normal individuals. The blood was centrifuged and the serum removed. The cells were washed four times in the centrifuge with an equal volume of Ringer-Locke's solution of the following composition: $\mathrm{NaCl}, 0.9$ gram per 100 cc.; $\mathrm{KCl}, 0.042 ; \mathrm{CaCl}_{2}$, $0.024 ; \mathrm{NaHCO}_{3}, 0.02$. No glucose was added. The $\mathrm{pH}$ of the solution by the method of Cullen (7) was 8.00. After washing, the corpuscles were laked by adding an equal volume of water and $3 \mathrm{mgm}$. of saponin per $1 \mathrm{cc}$. of cells. One-half volume of triple strength RingerLocke's solution was then added to make up the normal salt concentration. In each experiment two or three dilutions were prepared from the original concentration (which contained from 12 to 14 grams of hemoglobin per $100 \mathrm{cc}$. of solution). The concentration of hemoglobin in each solution was determined by the refractometric method of Stoddard and Adair (8). The readings of the Abbe refractometer were sharp for hemoglobin concentrations below 10 per cent, but much less accurate for the more concentrated solutions. The observed values of the lower concentrations were related to each other as their dilution factors, within \pm 0.2 per cent. In one experiment the concentrations of four solutions were determined also by the oxygen capacity method of Van Slyke. The values checked those of the refractometer within \pm 0.2 per cent hemoglobin.

\section{DATA}

Table I presents data relating to the effect of temperature on the osmotic pressure of blood serum and of hemoglobin solutions. The findings indicate that serum remains osmotically stable to variations in temperature from $10^{\circ} \mathrm{C}$. to $37^{\circ} \mathrm{C}$. during a sufficient period of time to allow the determinations to be carried out. The changes in osmotic pressure which occur under these conditions are reversible and are approximately of the magnitude to be expected on the assumption that serum behaves, osmotically, as an ideal solution. The possibility that cooling the serum below body temperature produces significant chemical or colloidal changes in the proteins is apparently ruled out. Consideration of the data on hemoglobin leads to similar conclusions. The determinations were carried out in duplicate. The " observed osmotic pressure change" was taken as the mean of the changes in pressure observed in the individual osmometers. The "theoretical change" was calculated from the mean of the pressure readings at the lowest temperature, on the assumption that pressure is proportional to absolute temperature. The ratio of the pressure change observed to that calculated in each case is given in the table. The variability of these ratios in individual experiments is to be attributed, in part at least, to variations in the capillarity of the solution in the osmometer tubes during the course of the experiment. The error of determining the average capillarity correction by observing the heights at which the rising and falling solution comes to rest in the osmometer tube at the end of the experiment should not appreciably affect the accuracy of the calculations, provided the actual forces of capillarity remained constant in each tube throughout the experiment (which often lasted 24 hours or longer). Various lines of evidence, such as 
TABLE I

The relation of the increase in osmotic pressure of human blood serum and hemoglobin solutions to changes in temperature, over different ranges, as compared with the changes which would be expected to occur in ideal solutions

\begin{tabular}{|c|c|c|c|c|c|c|c|c|c|c|}
\hline \multirow{2}{*}{ Sample } & \multirow{2}{*}{ Subject } & \multicolumn{7}{|c|}{ Ratios: $\frac{\text { observed osmotic pressure change }}{\text { theoretical change }}=\frac{\Delta \pi / \pi_{1}}{\Delta T / T}$} & \multicolumn{2}{|c|}{$\begin{array}{l}\text { Average ratio for all } \\
\text { temperature ranges }\end{array}$} \\
\hline & & $0^{\circ}-20^{\circ}$ & $0^{\circ}-25^{\circ}$ & $10^{\circ}-20^{\circ}$ & $10^{\circ}-30^{\circ}$ & $10^{\circ}-37^{\circ}$ & $15^{\circ}-35^{\circ}$ & $20^{\circ}-37^{\circ}$ & Serum & Hemoglobin \\
\hline 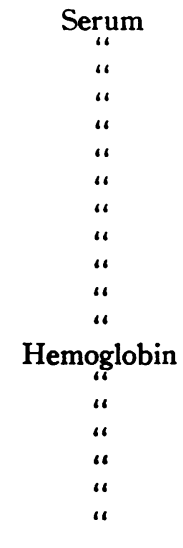 & $\begin{array}{l}\mathrm{Bi} \\
\mathrm{Ca} \\
\mathrm{Dr} \\
\mathrm{Ha} \\
\mathrm{Mi}(\mathrm{a}) \\
\mathrm{Mi}(\mathrm{b}) \\
\mathrm{Mi}(\mathrm{c}) \\
\mathrm{Mi}(\mathrm{d}) \\
\mathrm{Sm} \\
\mathrm{Sp} \\
\mathrm{We} \\
\mathrm{X} \\
\mathrm{Dr} \\
\mathrm{Dr} \\
\mathrm{Mo} \\
\mathrm{Mo} \\
\mathrm{Br} \\
\mathrm{Br} \\
\mathrm{Br}\end{array}$ & $\begin{array}{l}1.00 \\
1.35\end{array}$ & $\begin{array}{l}.935 \\
.840 \\
.792 \\
.910 \\
.885\end{array}$ & $\begin{array}{r}.537 \\
1.042 \\
.714 \\
1.065 \\
.729 \\
.975\end{array}$ & $\begin{array}{r}.910 \\
1.025 \\
.702 \\
.994\end{array}$ & $\begin{array}{r}.672 \\
1.020 \\
.648\end{array}$ & $\begin{array}{r}.720 \\
.690 \\
\\
.703 \\
1.440\end{array}$ & $\begin{array}{r}.775 \\
1.026\end{array}$ & $\begin{array}{r}.724 \\
1.028 \\
.648 \\
.708 \\
1.005 \\
.720 \\
.690 \\
.808 \\
.703 \\
.975 \\
.703 \\
1.440\end{array}$ & $\begin{array}{r}1.000 \\
1.350 \\
.935 \\
.840 \\
.792 \\
.910 \\
.885\end{array}$ \\
\hline Averages & & 1.175 & .872 & .843 & .895 & .788 & .888 & .847 & $.854 \pm .044^{*}$ & $.959 \pm .070^{*}$ \\
\hline
\end{tabular}

* Standard error of the mean.

the occasional appearance of grease or of small amounts of adsorbed protein at the meniscus, indicate that the capillarity was not always the same at the different levels to which the meniscus was brought by the various temperature changes. The magnitude of the errors of capillarity, while not great in comparison with the total osmotic pressure, must be relatively large in proportion to the changes in pressure produced by changes in temperature. Consequently, one can draw conclusions from the data only on the basis of average values of the ratios, which may be expected to smooth out the unavoidable errors of the present method.

In spite of the errors, it would appear that temperature has a larger effect on the osmotic pressure of serum of some subjects than of others. It would appear, also, that the ratio is approximately the same over the various temperature ranges studied. The mean of the ratios for all determinations on serum is $0.85 \pm .04$ (where \pm .04 is the standard error of the mean). The mean for hemoglobin is $0.96 \pm .07$, the greater standard error being due, in part, to the relative paucity of data on hemoglobin as compared to serum. The chances are about even that the true mean for serum may be as high as 0.89 and that the mean for hemoglobin may be as low as 0.89 ; consequently the difference between the observed means is not significant. The mean ratio for all the determinations, on serum and hemoglobin, is $0.88 \pm .04$. The standard deviation of the individual ratios about this mean is \pm 0.2 .

Although the mean values of the ratios, as found, are not sufficiently accurate to justify a discussion of their significance in relation to the theory of solutions, they do indicate that, for practical purposes, no great error will be introduced by employing a ratio of 1.0 (as for the case of ideal solutions) in calculating the osmotic pressure of serum or hemoglobin at different temperatures. This assumption allows the use of the simple formula, $\pi_{2}=\pi_{1} \mathrm{~T}_{2} / \mathrm{T}_{1}$, in which $\pi$ is the osmotic pressure, and $T$ is the absolute temperature. Employing this formula it is found, for example, that a correction of 6 per cent of the value of the osmotic pressure at $20^{\circ} \mathrm{C}$. should be added to give the approximate pressure at body temperature.

References in the literature to previous studies 
on the relation of temperature to the osmotic pressure of protein solutions are few, and the data have not been satisfactory. Martin (9), without publishing data, claimed to have found that GayLussac's law was obeyed exactly. Adair (10) employed the thermodynamic relations based on this law in calculating the pressure of hemoglobin at $0^{\circ} \mathrm{C}$. from some of his data which had been obtained in experiments at a higher temperature. Krogh and Nakazawa (11) failed to demonstrate any effect of temperature on the osmotic pressure of serum. Verney (12) was able to conclude that, while temperature has some effect on the osmotic pressure of serum, it is much less than that called for by the theory of ideal solutions.

TABLE II

Showing that, within the limits of error of the method, the same equilibrium pressure is obtained on the same sample of serum with membranes of widely different permeabilities. Osmotic pressure in $\mathrm{mm}$. of water at $20^{\circ} \mathrm{C}$.

\begin{tabular}{|c|c|c|c|c|}
\hline \multirow{2}{*}{ Subject } & \multicolumn{4}{|c|}{ Specific permeability ranges of membranes } \\
\hline & $\begin{array}{l}1 \text { to } 3 \\
\times 10^{-8}\end{array}$ & $\begin{array}{l}6 \text { to } 12 \\
\times 10^{-8}\end{array}$ & $\begin{array}{l}20 \text { to } 57 \\
\times 10^{-8}\end{array}$ & $\begin{array}{c}200 \text { to } 300 \\
\times 10^{-8}\end{array}$ \\
\hline Go & $m m . \mathrm{H}_{2} \mathrm{O}$ & $\begin{array}{c}m m . \mathrm{H}_{2} \mathrm{O} \\
448\end{array}$ & $\begin{array}{c}m m . \mathrm{H}_{2} \mathrm{O} \\
432\end{array}$ & $\begin{array}{c}m m . \mathrm{H}_{2} \mathrm{O} \\
431\end{array}$ \\
\hline $\mathrm{Ha}$ & & 450 & 442 & leak \\
\hline $\mathrm{Sp}$ & 352 & 348 & $\begin{array}{l}349 \\
349 \\
351\end{array}$ & \\
\hline $\mathrm{Mi}$ & 363 & 366 & $\begin{array}{l}366 \\
364 \\
360\end{array}$ & \\
\hline We (a) & 385 & & $\begin{array}{l}412 \\
400^{*} \\
397 \\
399 \\
382 \\
388\end{array}$ & \\
\hline We (b) & 390 & 393 & $\begin{array}{l}398 \\
401 \\
397 \\
395\end{array}$ & \\
\hline
\end{tabular}

* Ultrafiltrate as outer solution.

The data shown in Table II provide direct evidence of the complete impermeability of the membranes to all fractions of the serum proteins. Within the limits of error of the method, the same pressure is observed when membranes are used which are either much more (within limits) or much less permeable than the usual grade. It is probable that the membranes used in the standard osmotic pressure methods are much less permeable than the tightest membranes of our series (which did not usually require more than 8 to 12 hours for the attainment of equilibrium). Although some colloids may require tighter membranes, the specific permeability (3) range of 20 to $40 \times 10^{-8}$ would appear to be ideal for blood serum, hemoglobin, and in all probability for many other types of protein solutions. Equilibrium, with such membranes, may be attained within 3 to 12 hours, and the average time required to carry out the whole determination is approximately 8 hours.

The possibility that some property of the membrane, other than its permeability, may affect the value of the equilibrium pressure has already been ruled out, in our opinion, by the work of Turner (13), who obtained the same values for the osmotic pressure of serum with membranes composed of a variety of materials.

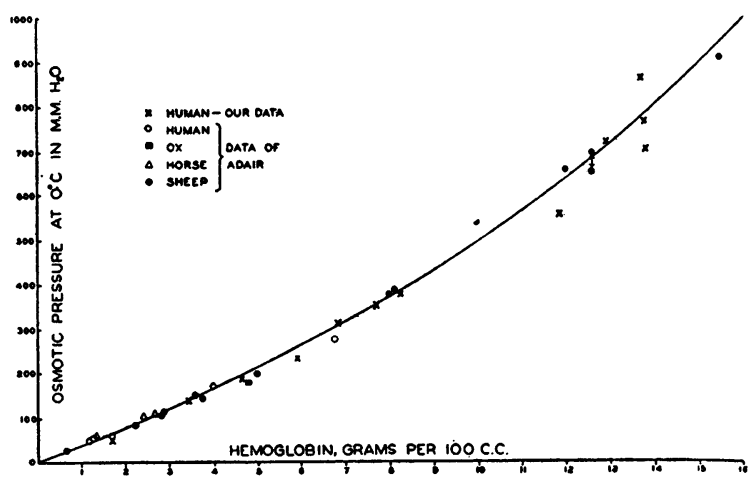

Fig. 1. Pressure-concentration graph of hemoglobinsalt solutions. Comparison of data obtained by the rapid method with values published by Adair. Curve, plotted from the formula, $\pi=37 \mathrm{Hb} / 1-0.0254 \mathrm{Hb}$, where $\pi$ is the pressure in $\mathrm{mm}$. of water at $0^{\circ} \mathrm{C}$. and $\mathrm{Hb}$ is the concentration of hemoglobin in grams per $100 \mathrm{cc}$. of hemoglobin-Ringer solution of $\mathrm{pH} 8.0$.

Figure 1 shows the relation of the osmotic pressure to the concentration of hemoglobin-Ringer solutions (prepared from the blood of four human subjects). It is to be noted that our values correspond very well with those obtained by Adair in his studies on solutions of hemoglobin, from various species. Adair (14) found that, in the presence of salts at a total concentration above $0.01 \mathrm{M}$., the osmotic pressure of hemoglobin is 
independent of the $\mathrm{pH}$, except at high concentrations of hemoglobin (above 6 to 10 per cent). Since we have employed the same $\mathrm{pH}$ which Adair used in most of his determinations $(\mathrm{pH}$ 8.00) and have made up our solutions with salts whose total concentration is considerably above $0.01 \mathrm{M}$. there is no reason to believe that the correspondence of our values with those of Adair can be attributable to chance. The pressure-concentration relations of hemoglobin solutions, as found by Adair, have previously been confirmed by others $(2,15)$.

It is probable that the degree of scattering of the points corresponding to the higher concentrations of hemoglobin is due in part to the relatively great effect of slight changes in salt concentration and of $\mathrm{pH}$ at concentrations of hemoglobin above 6 to 10 per cent (Adair (14)), and in part to the relative inaccuracy of the refractometric determination of the higher concentrations. In any case the data support the contention that the membranes used in our method are strictly semipermeable with respect to hemoglobin, and therefore, presumably, to serum proteins also.

The curve, drawn through the points of Figure 1 is plotted from the formula, $\pi=37 \mathrm{Hb} / 1-$ $0.0254 \mathrm{Hb}$, which was obtained by Adair (14) from his data on the hemoglobin of sheep. The equation corresponds to the form $\pi(\mathrm{v}-\mathrm{b})=\mathrm{k}$, in which $\mathrm{v}=100 / \mathrm{Hb}, \mathrm{b}=2.54$ and $\mathrm{k}=3700$. The pressure is expressed in $\mathrm{mm}$. of water and the concentration, $\mathrm{Hb}$, in grams per $100 \mathrm{cc}$. Adair finds that this equation expresses the relation of concentration to pressure (at $0^{\circ} \mathrm{C}$.) up to 20 per cent hemoglobin. Values of the osmotic pressure calculated by this formula may conveniently be employed for a comparison with observed values in tests which may be carried out in any laboratory to check the accuracy of an osmotic pressure method. Such tests may be carried out at any convenient temperature above $0^{\circ}$ C., for the corresponding pressure values may then be corrected to $0^{\circ} \mathrm{C}$. by the application of the equation, $\pi_{2}=\pi_{1} T_{2} / T_{1}$, which, as our studies have demonstrated, is applicable to hemoglobin solutions.

\section{SUM MARY}

Critical tests applied to the procedures in use in this laboratory for the determination of the osmotic pressure of proteins in biological fluids indicate that the method gives reliable results:

1. Serum is shown to remain osmotically stable to variations in temperature from $10^{\circ} \mathrm{C}$. to $37^{\circ}$ C. for a sufficient time to allow the determination to be carried out. Variations in temperature, within this range, produce changes in the osmotic pressure which are reversible and which are of the magnitude to be expected from the theory of ideal solutions.

2. The membranes employed are completely impermeable to the serum proteins, for their permeability may be either decreased or increased, over a wide range of specific permeability values, without affecting the value of the observed osmotic pressure.

3. The osmotic pressure of hemoglobin solutions, as determined by the rapid method, are identical, within the limits of error, with values established by others, who have used the "slow" methods hitherto considered essential for accurate studies. The practicability of the use of hemoglobin solutions, for the standardization of osmotic pressure methods in all laboratories is emphasized.

4. The rapid method, standardized as indicated, appears to be sufficiently reliable to warrant its use in many types of investigations of the osmotic properties of proteins.

\section{BIBLIOGRAPHY}

1. Adair, G. S., A critical study of the direct method of measuring the osmotic pressure of haemoglobin. Proc. Roy. Soc., Lond., s. A, 1925, 108, 627.

2. Burk, N. F., and Greenberg, D. M., The physical chemistry of the proteins in non-aqueous and mixed solvents. I. The state of aggregation of certain proteins in urea-water solutions. J. Biol. Chem., 1930, 87, 197.

3. Wells, H. S., Some criteria of accuracy for the measurement of the osmotic pressure of colloids in biological fluids. Am. J. Physiol., 1932, 101, 409.

4. Wells, H. S., A modified Krogh osmometer for the determination of the osmotic pressure of colloids in biological fluids (with directions for its use). J. Tenn. Acad. Sc., 1933, 8, 102.

5. Wells, H. S., The concentration and osmotic pressure of the proteins in blood serum and in lymph from the lacteals of dogs. Am. J. Physiol., 1932, 101, 421.

6. Wells, H. S., Youmans, J. B., and Miller, D. G., Jr., $A$ formula and nomogram for the estimation of 
the osmotic pressure of colloids from the albumin and total protein concentrations of human blood sera. J. Clin. Invest., 1933, 12, 1103.

7. Cullen, G. E., Studies of acidosis. XIX. The colorimetric determination of the hydrogen ion concentration of blood plasma. J. Biol. Chem., 1922, 52, 501.

8. Stoddard, J. L., and Adair, G. S., The refractometric determination of hemoglobin. J. Biol. Chem., 1923, 57, 437.

9. Martin, C. J., A rapid method of separating colloids from crystalloids in solutions containing both. $\mathrm{J}$. Physiol., 1896, 20, 364.

10. Adair, G. S., The osmotic pressure of hemoglobin in the absence of salts. Proc. Roy. Soc., London, s. A, 1925, 109, 292.

11. Krogh, A., and Nakazawa, F., Beiträge zur Messung des kolloidosmotischen Druckes in biologischen Flüssigkeiten. Biochem. Ztschr., 1927, 188, 241.

12. Verney, E. B., The osmotic pressure of the proteins of human serum and plasma. J. Physiol., 1926, 61, 319.

13. Turner, A. H., The validity of determinations of the colloid osmotic pressure of serum. J. Biol. Chem., 1932, 96, 487.

14. Adair, G. S., A theory of partial osmotic pressures and membrane equilibria, with special reference to the application of Dalton's Law to haemoglobin solutions in the presence of salts. Proc. Roy. Soc., London, s. A, 1928, 120, 573.

15. McCarthy, E. F., A comparison of fetal and maternal haemoglobins in the goat. J. Physiol., 1933, 80, 206. 